\title{
A Memory Already like an Elephant's? The Advanced Brain Morphology of the Last Common Ancestor of Afrotheria (Mammalia)
}

\author{
Julien Benoit ${ }^{a}$ Nick Crumpton ${ }^{c}$ Samuel Mérigeaud ${ }^{b}$ Rodolphe Tabuce $^{a}$ \\ a Institut des Sciences de I'Evolution UMR-CNRS 5554, cc064, Université Montpellier 2, and \\ bService d'Imagerie Médicale Hôpital Lapeyronie, CHU de Montpellier, Montpellier, France; \\ ${ }^{\mathrm{C}}$ Mammal Evolution and Morphology Group, University Museum of Zoology, Cambridge, UK
}

\section{Key Words}

Neopallium · Endocast · Ungulate grade · Insectivore grade . Afrotheria - Ancestor

\begin{abstract}
Virtually reconstructed and natural endocranial casts are used in the study of brain evolution through geological time. We here present work investigating the paleoneurological evolution of afrotherian mammals. Using microCT-generated endocasts we show that, with the exception of the subfamilies Macroscelidinae and Tenrecoidea, most Afroinsectiphilia display a more or less gyrencephalic and ventrally expanded neopallium, two derived features that are unexpected for these insectivore-grade afrotherians. This implies that the endocranial cast morphology at the root of the afrotherian clade may have been more advanced than previously thought. The reconstructed endocranial morphology of the Afrotheria's last common ancestor reaches the level of complexity of some early Cenozoic archaic ungulates. Our result gives support to the hypothesis of an ungulate-like ancestral body plan for Afrotheria. It also implies that the a priori 'primitive' suite of traits evident in the brain of Afroinsectivora, especially in the tenrecs, may have been secondarily acquired. Implications on the overestimation of the divergence age of Afrotheria are discussed.
\end{abstract}

Copyright $\odot 2013$ S. Karger AG, Basel

\section{Introduction}

Afrotheria is a clade of placental mammals that includes the extant Proboscidea (elephants), Sirenia (sea cows), Hyracoidea (hyraxes), Tenrecoidea [Tenrecidae (tenrecs) plus Chrysochloridae (golden moles)], Macroscelidea (elephant shrews) and Tubulidentata (aardvarks) [Stanhope et al., 1998; Springer et al., 2004; Poulakakis and Stamatakis, 2010; Kuntner et al., 2011]. The former three orders (Proboscidea, Hyracoidea and Sirenia) form, with their extinct relatives (Embrithopoda and Desmostylia), a clade of hoofed mammals called Paenungulata. A more restrictive clade, called Tethytheria, includes the same orders with the exception of Hyracoidea [Tabuce et al., 2008]. The remaining three orders of insectivorous afrotherians and their extinct relatives (e.g. Bibymalagasia, the Malagasy aardvarks) are nested in the Afroinsectiphilia [Asher and Hulgen, 2010] (fig. 1). Among extant Afrotheria, Paenungulata have large, curved brains with proportionally small olfactory bulbs. They have a folded (gyrencephalic) and huge neocortex expending ventrolaterally so that the rhinencephalon is not exposed in lateral view (microsmatic), their midbrain is not exposed dorsally because the mesencephalon (including corpora quadrigemina) is covered by the neocortex in dorsal view, and they have reduced floccular lobes of the cerebellum [Owen, 1868; Elliot Smith, 1902; Nieuwenhuys et al., 1998]. Because these characters

\section{KARGER}

E-Mail karger@karger.com

www.karger.com/bbe
(C) 2013 S. Karger AG, Basel

0006-8977/13/0813-0154\$38.00/0
Julien Benoit

Institut des Sciences de l'Evolution UMR-CNRS 5554, cc064

Université Montpellier 2, place Eugène Bataillon

FR-34095 Montpellier cedex 05 (France)

E-Mail julien.benoit@univ-montp2.fr 


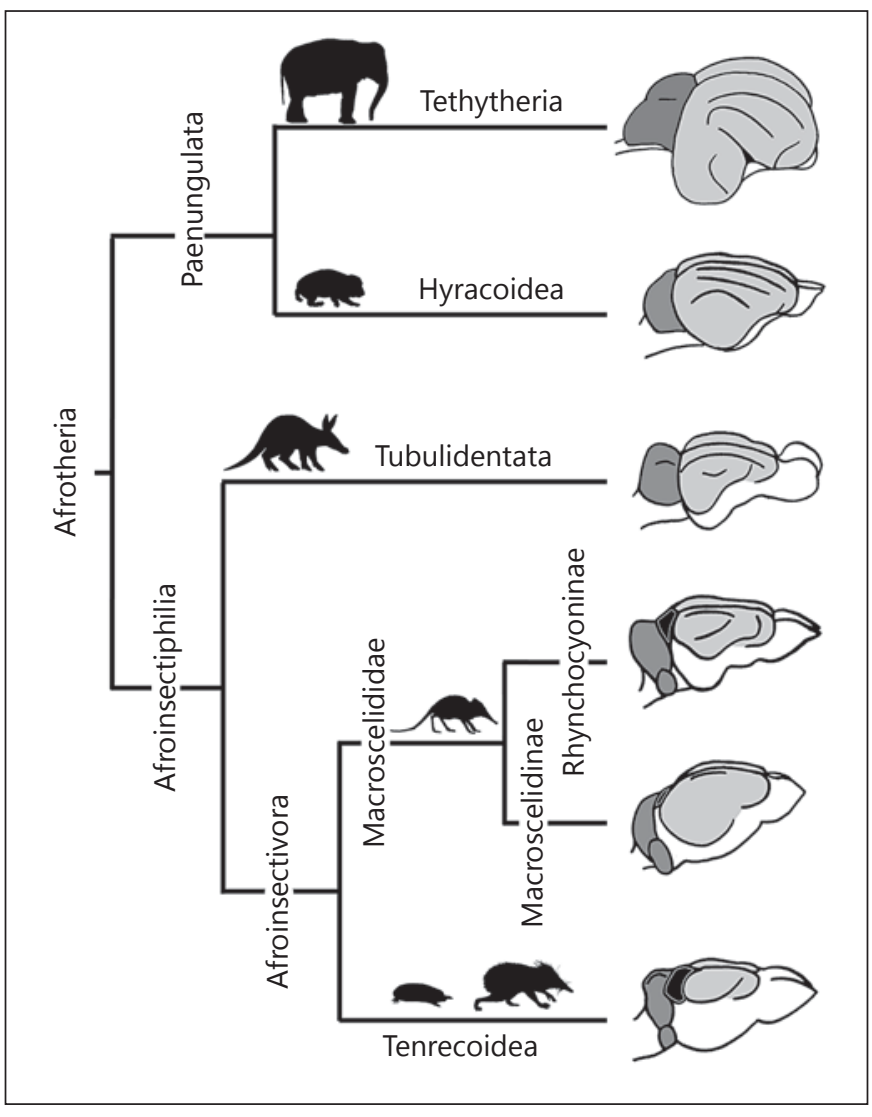

Fig. 1. Phylogeny and brain morphology of Afrotheria. The neopallium is light grey, the midbrain is black and the cerebellum is dark grey. Drawings are not to scale to emphasize morphological comparison.

are present in modern hoofed mammals (Paenungulata, Ferungulata) and anthropoid Primates, it is commonly assumed that they are derived with respect to the ancestral eutherian condition: a small linearly organised brain with small and smooth neocortex (lissencephalic), hugely exposed rhinencephalon (macrosmatic) in lateral view, proportionally large olfactory bulbs, large midbrain exposure and large flocullar lobes [Elliot Smith, 1902; Edinger, 1948, 1956; Dechaseaux, 1962; Edinger, 1964; Kielan-Jaworowska, 1986; Jerison, 1973; Nieuwenhuys et al., 1998; Macrini et al., 2007; Rowe et al., 2011]. Afroinsectiphilia show a wide range of brain morphologies. On one hand, the Tenrecoidea (Chrysochloridae, Tenrecidae) and some Macroscelididae (namely those belonging to the subfamily Macroscelidinae) typically display the so-called 'primitive' eutherian condition [Le Gros Clark, 1932; Edinger, 1948; Jerison, 1973; Nieuwenhuys et al., 1998]. On the other hand, Rhynchocyon (Macroscelididae, subfamily Rhyn- chocyoninae) and Orycteropus (Tubulidentata) have more advanced brain morphologies. Rhynchocyon, which is the basal-most genus of Macroscelididae [Corbet, 1995; Douady et al., 2003; Kuntner et al., 2011] and is sometimes considered a 'living fossil' [Novacek, 1984], bears three distinct sulci on its neopallium [Owen, 1868; Bauchot and Stephan, 1967]. As in other Macroscelididae, its brain is a little more encephalized than other Afroinsectiphilia and its neocortex is larger [Bauchot and Stephan, 1967; Jerison, 1973]. The brain of Orycteropus also bears at least three sulci and there is neither midbrain exposure nor prominent floccular lobes [Elliot Smith, 1899, 1902; Sonntag and Woollard, 1925; Friant, 1960; Thewissen, 1985]. To find such advanced characters in both major clades of Afrotheria strongly suggests that they were already present in the last common ancestor of Afrotheria (LCA). Following this hypothesis, the ancestral brain morphology of afrotherians would have looked quite different from that of stem eutherians. The alternative hypothesis is that these derived traits appeared convergently in each clade.

In the present study, we have investigated the brain and endocranial cast morphology of extant and fossil afrotherians in order to test these hypotheses. Endocranial casts are a material of choice to compare fossil taxa with extant species because their morphology is nearly identical to that of the outer surface of the brain itself in most mammals [Edinger, 1948; Dechaseaux, 1962; Bauchot and Stephan, 1967; Jerison, 1973]. Although data on brain and endocranial cast are published for most groups (see Material and Methods), no survey on the evolution of the endocranial cast among afrotherians has been conducted so far. The new techniques of non-destructive investigations by the use of X-ray microtomography allow the study of endocranial casts which were hardly accessible before [Rowe et al., 2011; Orliac et al., 2012]. This technology is of particular interest for palaeontologists who are now able to see the internal structures of some rare extant species and unique fossil specimens without destroying or damaging them. Endocasts of living and fossil afrotherians which were not accessible before can now be studied in silico and can provide new insight into the evolutionary history of early afrotherians' brain.

\section{Material and Methods}

The Accuracy of Endocranial Cast to Reconstruct Brain Morphology

Endocranial casts (or endocasts) are casts of the brain cavity and include prints of the meninx, cranial nerves, blood vessels and veinous sinuses between the dura mater and the periost [Bauchot 
and Stephan, 1967]. Thus, the endocast is not an exact cast of the brain. Nevertheless, in the context of a paleoneurologic study, it is the only element that can be compared between extant and extinct animals [Edinger, 1948; Dechaseaux, 1962]. Additionally, marks left by the neopallium on the endocranial cast are often identical to the real sulcal pattern of the neocortex in life, except in the case of a thickening of the meninx as it occurs in Tethytheria and Cetacea [Dechaseaux, 1962]. Accordingly, neocortex and neopallium are used here interchangeably. To avoid any error in the interpretation of the sulcal pattern of the endocranial casts, our data were systematically compared to published pictures of real brains when available (online suppl. data 1; for all online suppl. material, see www.karger.com/doi/10.1159/000348481). The result was that none of our samples deviate from the pattern observed on the fleshy outer surface of the brain.

\section{Taxon Sampling}

The morphology of the fleshy brain has been described in many of the living representatives of Afrotheria (online suppl. data 1) and the morphology of the endocranial cast is also known in many fossil representatives such as Pleistocene hyracoids [Wells, 1939], the embrithopod Arsinoitherium [Andrews, 1906], the proboscideans Moeritherium, Mammut and Mammuthus [Andrews, 1906; Dechaseaux, 1958a], numerous Paleogene and Neogene sirenians [Edinger, 1933; Pilleri, 1990; Furusawa, 2004], the bibymalagasian Plesiorycteropus [Thewissen, 1985; MacPhee, 1994] and to a lesser degree in the desmostylian Desmostylus [Edinger, 1975]. To make our reconstruction of the endocranial morphology of the LCA of afrotherians as accurate as possible, we scanned and digitally reconstructed the brain of some key fossil taxon (see online suppl. data 1).

\section{Paenungulata}

The Procaviidae are the only living family of Hyracoidea. Within procaviids, the endocranial morphology is quite similar in extant and fossil species [Wells, 1939]. Thus, in addition to extant species, the endocasts of two Paleogene hyracoids were also studied. Seggeurius amourensis, from the early Eocene of El Kohol (Algeria), represents the earliest and most plesiomorphic hyracoid yet know [Court and Mahboubi, 1993; Seiffert, 2007; Tabuce et al., 2008]. We used an undescribed cranium found associated with the mandible UOK-210 described by Crochet [in Mahboubi et al., 1986] and later by Court and Mahboubi [1993]. The second hyracoid endocranial cast belongs to Saghatherium antiquum (SMNS 12621), which represents a more advanced species from the Fayum [Rasmussen and Gutierrez, 2010]. Prorastomus sirenoides (BMNH 44897 ) is the basal-most sirenian and one of the earliest Tethytheria for which the skull is known [Gheerbrant et al., 2005; Tabuce et al., 2007].

\section{Afroinsectiphilia}

Bibymalagasia (or Malagasy aardvarks) is an extinct order of Malagasy mammals represented by the Quaternary genus Plesiorycteropus [Patterson, 1975; MacPhee, 1994]. Since the discovery of the clade Afrotheria, the sister-group relationship between Bibymalagasia and Tubulidentata has been supported by several phylogenetic analyses [Asher et al., 2003; Horovitz, 2004; Asher, 2005; Holroyd and Mussell, 2005; Asher, 2007] and their place in Afrotheria is largely accepted [Kemp, 2005; Beck et al., 2006; Hol- royd, 2010]. Although the genus Plesiorycteropus became extinct recently, the origin of bibymalagasians likely dates back from the Eocene or even earlier, when the ancestors of this lineage split from Tubulidentata and reached Madagascar [Patterson, 1975]. The two known skulls of Plesiorycteropus (MAD 327 and MAD 328) were both scanned. We also scanned the skull of a Pliocene tubulidentate from France (Amphiorycteropus depereti, Rs 555) belonging to a different genus than the extant aardvark. Unfortunately, no endocast of fossil Macroscelididae and Tenrecoidea were available for this study, primarily because no significant cranial remains are known prior to the Neogene [Seiffert, 2002; Benoit et al., 2013].

The Procaviidae are the only living family of Hyracoidea. Within procaviids, the endocranial morphology is very similar in extant and extinct species [Wells, 1939]. In addition to extant species, the endocasts of two Paleogene hyracoids were also studied. S. amourensis, from the early Eocene of El Kohol (Algeria), represents the earliest and most plesiomorphic hyracoid yet know [Court and Mahboubi, 1993; Seiffert, 2007; Tabuce et al., 2008]. We used a cranium still undescribed, found associated with the mandible UOK-210 described by Crochet [in Mahboubi et al., 1986] and later by Court and Mahboubi [1993]. The second hyracoid endocranial cast belongs to Saghatherium antiquum (SMNS 12621], Oligocene of the Fayum, which represents a more advanced species [Rasmussen and Gutierrez, 2010].

\section{Measurements}

The Neo/Rhin (table 1, column B) ratio was calculated as the quotient between the maximum height of the neopallium and the maximum height of the rhinencephalon when viewed in lateral view (see online suppl. data 2 ). This value was complimented by generating the ratio between the surfaces of the neopallium and the rhinencephalon (table 1, column $\mathrm{C}$ ). These two measures give congruent results (table 1). We also computed ratios between olfactory bulbs, cerebellum and total endocranial cast volumes (table 1). We use the encephalization quotient (EQ) defined by Jerisson [1973] EQ = brain mass/0.12(body mass) ${ }^{2 / 3}$ in order to investigate the evolution of brain size across Afrotherians, primarily because it is the more widespread in the literature dealing with Afrotherian brains [Jerisson, 1973; Shoshani et al., 2006]. The EQ is a value to describe relative brain mass across mammalian species. A species with an EQ greater than 1 has a larger brain than expected for its body mass while a species with an EQ smaller than 1 has a smaller brain than expected for its body mass. We computed the EQ on our sample and we completed it mainly with the large databases of Shultz and Dunbar [2010] and Boddy et al. [2012] (online suppl. data 3). All measurements were done using Avizo 6.3 VSG software.

\section{Reconstruction of the LCA}

To reconstruct the morphology of the LCA as well as the evolution of discrete and continuous brain traits across afrotherian phylogeny, we used a parsimony model of ancestral states reconstruction using Mesquite 2.6 [Madisson and Madisson, 2009] on our EQ dataset and character matrix (table 2). The phylogenetic tree used for the reconstruction of ancestral states is a strict consensus mainly based on the works of Asher et al. [2003], Seiffert [2007] and Kuntner et al. [2011]. We also used the works of Gheerbrant et al. [2005], Lehmann [2009], Smit et al. [2011] and Velez-Juarbe 
Table 1. Measurements

\begin{tabular}{|c|c|c|c|c|c|c|c|c|}
\hline \multirow[t]{10}{*}{ Macroscelididae } & Rhynchocyon & cirnei & MNHN-1897-622 & 5,802 & 0.88 & 0.62 & 6.8 & 21.4 \\
\hline & & & MNHN-1897-624 & 5,602 & 0.91 & 0.61 & 7.0 & 15.6 \\
\hline & & & MNHN-1891-265 & 5,007 & 0.82 & 0.63 & 8.8 & 17.1 \\
\hline & Rhynchocyon & petersi & ZMB-84895 & 5,340 & 0.88 & 0.69 & 9.2 & 22.0 \\
\hline & Rhynchocyon & chrysopygus & ZMB-10925 & 5,776 & 0.98 & 0.68 & 9.3 & 21.9 \\
\hline & Macroscelides & proboscideus & MNHN-555 & 1,241 & 1.05 & 0.73 & 6.2 & 11.5 \\
\hline & Elephantulus & rozeti & MNHN-1986-1056 & 1,234 & 1.44 & 0.81 & 5.7 & 20.2 \\
\hline & & & MNHN-1913-441C & 1,299 & 1.58 & 0.96 & 4.9 & 20.6 \\
\hline & & & ZMB-6520 & 1,079 & 1.64 & 0.88 & 5.1 & 19.0 \\
\hline & Elephantulus & rupestris & MNHN-2006-552 & 1,270 & 1.27 & 0.90 & 5.2 & 23.4 \\
\hline \multirow[t]{8}{*}{ Tenrecoidea } & Potamogale & velox & MNHN-1947-864 & 4,044 & 0.30 & 0.25 & 2.9 & 24.6 \\
\hline & & & MNHN-1947-866 & 4,412 & 0.38 & 0.26 & 2.5 & 27.2 \\
\hline & Tenrec & eucaudatus & UM2-N-439 & 2,180 & 0.18 & 0.21 & 13.5 & 20.1 \\
\hline & & & UM2-N-80 & 2,419 & 0.25 & 0.17 & 15.7 & 21.0 \\
\hline & Microgale & dobsoni & MNHN-1962-2507 & 633 & 0.43 & 0.33 & 10.3 & 23.2 \\
\hline & & & MNHN-1962-2508 & 572 & 0.49 & 0.21 & 9.8 & 21.7 \\
\hline & Chrysochloris & asiatica & MNHN-1962-2583 & 531 & 0.22 & 0.20 & 7.0 & 3.2 \\
\hline & & & MNHN-A7024 & 693 & 0.11 & 0.37 & 8.4 & 6.3 \\
\hline \multirow[t]{2}{*}{ Tubulidentata } & Amphiorycteropus & depereti & Rss-55 & 70,637 & 2.20 & 0.82 & 9.8 & 21.1 \\
\hline & Orycteropus & afer & MNHN-1951-435 & 115,449 & 1.89 & 0.57 & 9.1 & 23.1 \\
\hline & Seggeurius & amourensis & UOK-210 & 4,942 & $? 4.10$ & NA & NA & $\mathrm{NA}$ \\
\hline Sirenia & Prorastomus & sirenoides & BMNH 44897 & 86,865 & NA & NA & 3.5 & 21.2 \\
\hline
\end{tabular}

A: Endocast volume $\left(\mathrm{mm}^{3}\right) ; \mathrm{B}$ : Neo/Rhin ratio; C: ratio between the surface of the neopallium and that of the rhinencephalon; D, E: relative volume of the olfactory bulbs (D) and the cerebellum (E) with respect to the endocast.

et al. [2012] to ascertain the phylogenetic position of some macroscelid species, Amphiorycteropus and fossil sirenians. The tree is unrooted in order to minimize assumptions on character polarity and because of uncertainties on the sister-group relationship of Afrotheria [Tabuce et al., 2008]. Given the highly derived conditions of modern elephant and sea cow EQs [Jerison, 1973; O'Shea and Reep, 1990], we choose to perform two analyses, one including and one excluding modern forms of proboscideans (Elephantimorpha) and sirenians.

Paleoneurology of Afrotheria

\section{Results}

\section{Description and Comparison}

Tubulidentata and Bibymalagasia

The neopallial morphologies of the extant aardvark and that of Plesiorycteropus have been described several times [Elliot Smith, 1899, 1902; Sonntag and Woollard, 1925; Friant, 1960; Thewissen, 1985; MacPhee, 1994; 
Table 2. Character matrix for the discrete character state reconstruction

\begin{tabular}{|c|c|c|c|c|c|c|c|c|c|c|c|c|c|c|c|c|c|c|}
\hline & 1 & 2 & 3 & 4 & 5 & 6 & 7 & 8 & 9 & 10 & 11 & 12 & 13 & 14 & 15 & 16 & 17 & 18 \\
\hline Chrysochloridae & 0 & 1 & 0 & 0 & - & - & 0 & - & 0 & 0 & 0 & - & 1 & 0 & 1 & 0 & 0 & 1 \\
\hline Tenrecidae & 1 & 0,1 & 0 & 0,1 & 1 & - & 0 & - & 0 & 0 & 0 & - & 0 & 0 & 1 & 0 & 0 & 1 \\
\hline Macroscelidinae & 1 & 1 & 0 & 0,1 & 1 & - & 0 & - & 0 & 1 & 0 & - & 1 & 1 & 1 & 0 & 0 & 1 \\
\hline Rhynchocyoninae & 1 & 1 & 0 & 1 & 1 & 0 & 1 & 0 & 1 & 0 & 0 & 1 & 0 & 0 & 1 & 0 & 0 & 1 \\
\hline Tubulidentata & 1 & 0 & 0 & 1 & 1 & 1 & 1 & 0 & 1 & 0 & 0 & 0 & 0 & 1 & 1 & 0 & 0 & 0 \\
\hline Bibymalagasia & 1 & 0 & 0 & 1 & 1 & 1 & 1 & 0 & 1 & 0 & 0 & 1 & 0 & 1 & 1 & 0 & 0 & 0 \\
\hline Procaviidae & 0 & 0 & 0 & 1 & 0 & 0 & 1 & 1 & 1 & 1 & 0 & 0 & 1 & 1 & 0 & 1 & 1 & 0 \\
\hline Tethytheria & 0,1 & 0 & 1 & 1 & 0 & 0 & 1 & 1 & 1 & 0,1 & 1 & 0 & 1 & 1 & 0 & 1 & 1 & 0 \\
\hline
\end{tabular}

Character list: 1, arrangement of the brain (curved: 0; linear: 1); 2, midbrain exposure (present: 1 ; absent: 0 ); 3 , thickening of the meninx (present: 1; absent: 0); 4, praesylvia (present: 1; absent: 0); 5 , praesylvia contact the posterior rhinal fissure (present: 1 ; absent, contact the anterior rhinal fissure: 0$) ; 6$, praesylvia contact the sulcus lateralis (present: 1 ; absent: 0 ); 7 , suprasylvia (present: 1 ; absent: 0 ); 8 , arched suprasylvia (present: 1 ; absent: 0); 9 , sulcus lateralis (present: 1 ; absent: 0 ); 10, intercalary sulcus (present: 1 ; absent: 0 );
11, pseudosylvia (present, very deep: 1; absent: 0 ); 12, almondshaped suprasylvian gyrus (present: 1; absent, rectilinear gyrus: 0); 13, sylvian fossa or orbital excavation (present: 1; absent: 0); 14, $\mathrm{Neo} /$ Rhin ratio $(>1: 1 ;<1: 0) ; 15$, microsmatic or macrosmatic brain (microsmatic: 1; macrosmatic brain: 0); 16, temporal lobes (prominent: 1 ; reduced: 0 ); 17 , contact between the posterior and the anterior rhinal fissures (present, rhinal fissure continuous: 1; absent: $0) ; 18$, floccular lobes (prominent: 1 ; reduced or absent: 0 ).
Nieuwenhuys et al., 1998]. The olfactory bulbs of Bibymalagasia (Plesiorycteropus germainepetterae) are less than twice as voluminous as those of Tubulidentata (table 1). Contrary to Orycteropus [Edinger, 1956], there is no evidence on the endocranial cast that the olfactory bulbs of Bibymalagasia display olfactory tracts in every direction on their dorsal and lateral aspects. In Bibymalagasia and Tubulidentata, the brain is linearly arranged (fig. 2a, b) and the telencephalon is only slightly macrosmatic, with a Neo/Rhin ratio that exceeds 1 (table 1). The relative surface of the neopallium with respect to the surface of the rhinencephalon is especially enlarged in P. germainepetterae (table 1). The neopallium bears three sulci: a praesylvia located rostroventrally, a sulcus lateralis located medially, and a suprasylvia located laterally to the sulcus lateralis. A faint ectosylvia could also be present. The praesylvia extend from the posterior rhinal fissure. In both taxa, it joins the sulcus lateralis rostrally (fig. 2a, b). According to the parsimony reconstruction of ancestral character states (fig. 3b) Bibymalagasia and Tubulidentata are unique among afrotherians by the presence of this contact between the praesylvian and the lateral sulci. While the suprasylvia is always faint if ever present in Orycteropus [Thewissen, 1985], it is always present and well marked in Plesiorycteropus. Moreover, the suprasylvia is more extended rostrally in Plesiorycteropus. In this taxon, the suprasylvia and the sulcus lateralis join each other rostrally and define an almond-shaped gyrus III (suprasylvian gyrus) in dorsal view (fig. 2b). Finally, the mesencephalon is entirely hidden in dorsal view and the floccular lobe of the cerebellum is reduced.

\section{Macroscelidea and Tenrecoidea (Afroinsectivora)}

The EQ of Afroinsectivora is usually low, especially in the Tenrecinae where the reconstructed ancestral value equals 0.36 (table 3 ). The olfactory bulbs are relatively large except in Potamogale, probably because of adaptation to aquatic lifestyle [Bauchot and Heinz, 1968]. Among Macroscelididae, Rhynchocyoninae have the more voluminous olfactory bulbs (table 1 ). The neopallium of Tenrecoidea is macrosmatic and smooth (fig. 2g, h). A short praesylvia is nonetheless present in some Tenrecidae such as Tenrec and Microgale, but not in Potamogale [Bauchot and Stephan, 1967, 1970]. As in macroscelides the midbrain is exposed in Tenrecoidea (except Potamogale). It consists of the posterior colliculi in both Tenrecidae and Chrysochloridae [Le Gros Clark, 1932; Bauchot and Stephan, 1967; Stephan and Bauchot, 1970]. Note that in tenrecine tenrecids the sagittal and transverse venous sinuses cover the midbrain on the endocranial cast (fig. $2 \mathrm{~g}$ ) but not on the membranous brain itself [Le Gros Clark, 1932; Bauchot and Stephan, 1967]. The floccular lobe of the cerebellum is developed in all Afroinsectivora. The brain is straight except in Chrysochloridae in which the hemispheres are anteroposteriorly compressed [Stephan and Bauchot, 1960] (fig. 2h). 


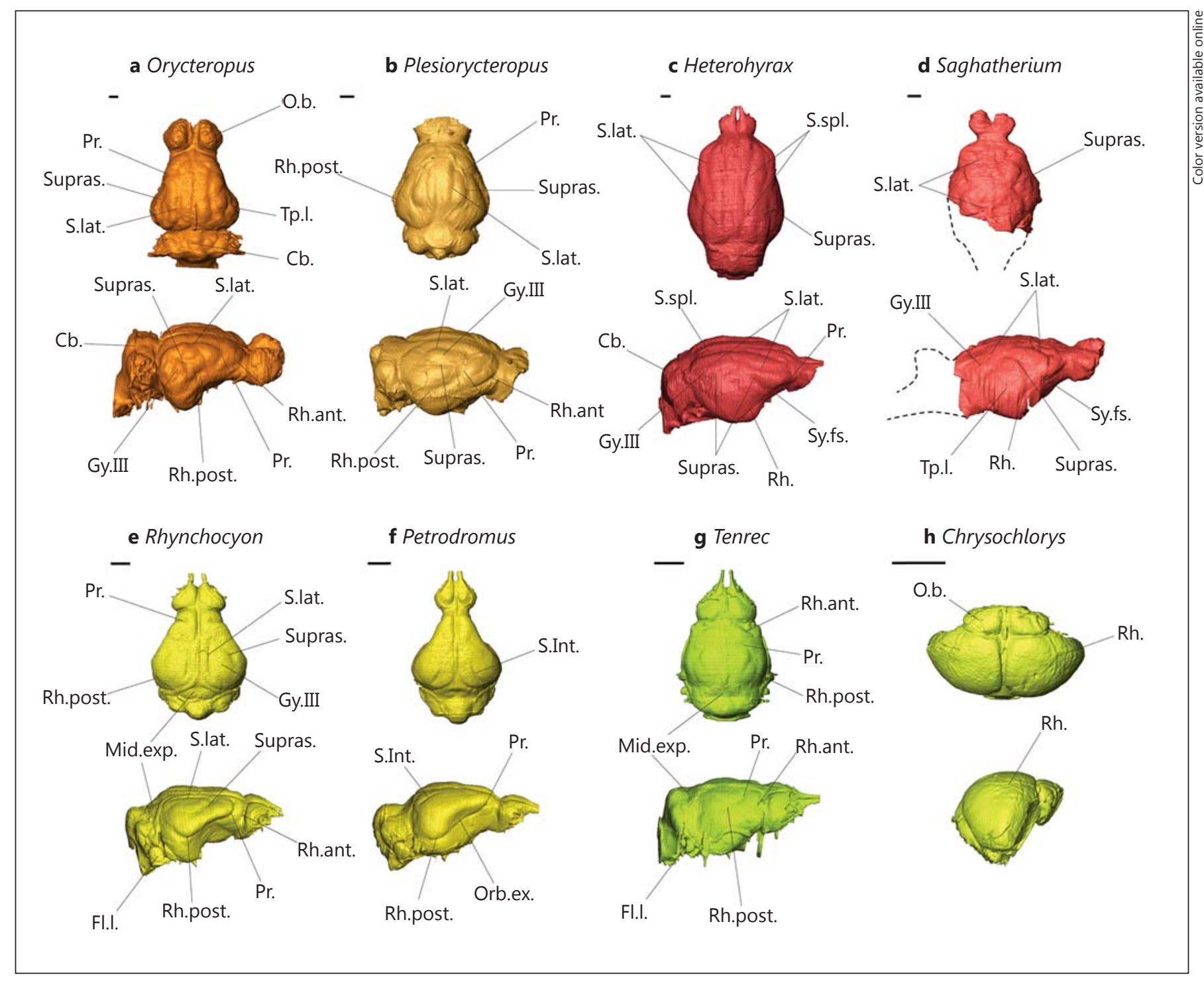

Fig. 2. Endocranial casts of various afrotherians in dorsal and dorsolateral views. Cb. = Cerebellum; Fl.1. = floccular lobe; Gy.III = suprasylvian gyrus (gyrus arcuatus III); Mid.exp. = midbrain exposure; O.b. = olfactory bulb; Orb.ex. = orbital excavation; Pr. = praesylvia; Rh. = rhinal fissure; Rh.ant. = anterior rhinal fissure; Rh.post. = post rhinal fissure; S.Int. = intercalary sulcus; S.lat. = sulcus lateralis; S.spl. = splenial sulcus; Supras. = suprasylvia; Sy.fs. = sylvian fossa; Tp.l. $=$ temporal lobe. Scale bar $=5 \mathrm{~mm}$.

Though similar, the endocranial casts of Macroscelididae differ from that of Tenrecoidea in many respects: the brain is relatively larger (reconstructed ancestral EQ averaging 0.7 ; table 3 ), the telencephalon is only slightly macrosmatic (Neo/Rhin ratio $>1$, table 1$)$ and strongly tapers anteriorly in dorsal view (fig. 2e, f). Among Macroscelidinae, which comprises all living genera except Rhynchocyon, the neopallium is larger than long, the $\mathrm{Neo} /$ Rhin ratio always exceeds 1 (while it is slightly below this value in Rhynchocyon, see table 1), there is an orbital excavation in the first half of the brain that is absent in Rhynchocyon and the neopallium bears a short sulcus posteriorly (fig. $2 \mathrm{f}$ ). This short sulcus was identified as the intercalary sulcus by Le Gros Clark [1928] because it separates the retrosplenial area (a part of the cingulate gyrus) and the visual area (a part of the lateral gyrus). In most mammals, the intercalary sulcus (or splenial sulcus) is restricted to the mesial face of the brain and cannot be seen 


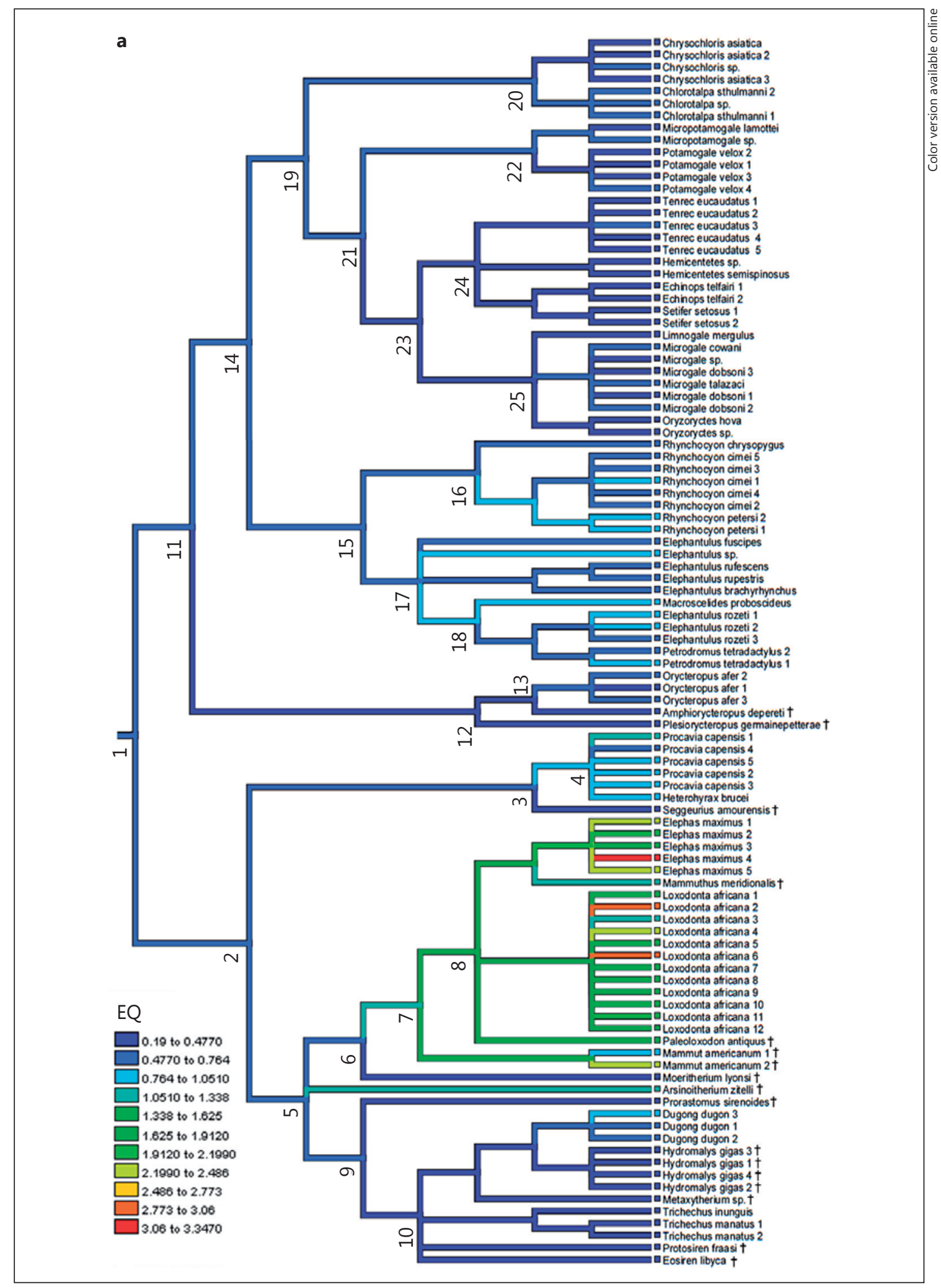

Fig. 3. Reconstruction of the endocranial morphology of the LCA of afrotherians. a Result of the character state reconstruction on the full dataset showing the evolution of EQ across Afrotheria. Labels at nodes correspond to node numbers in table 3. 


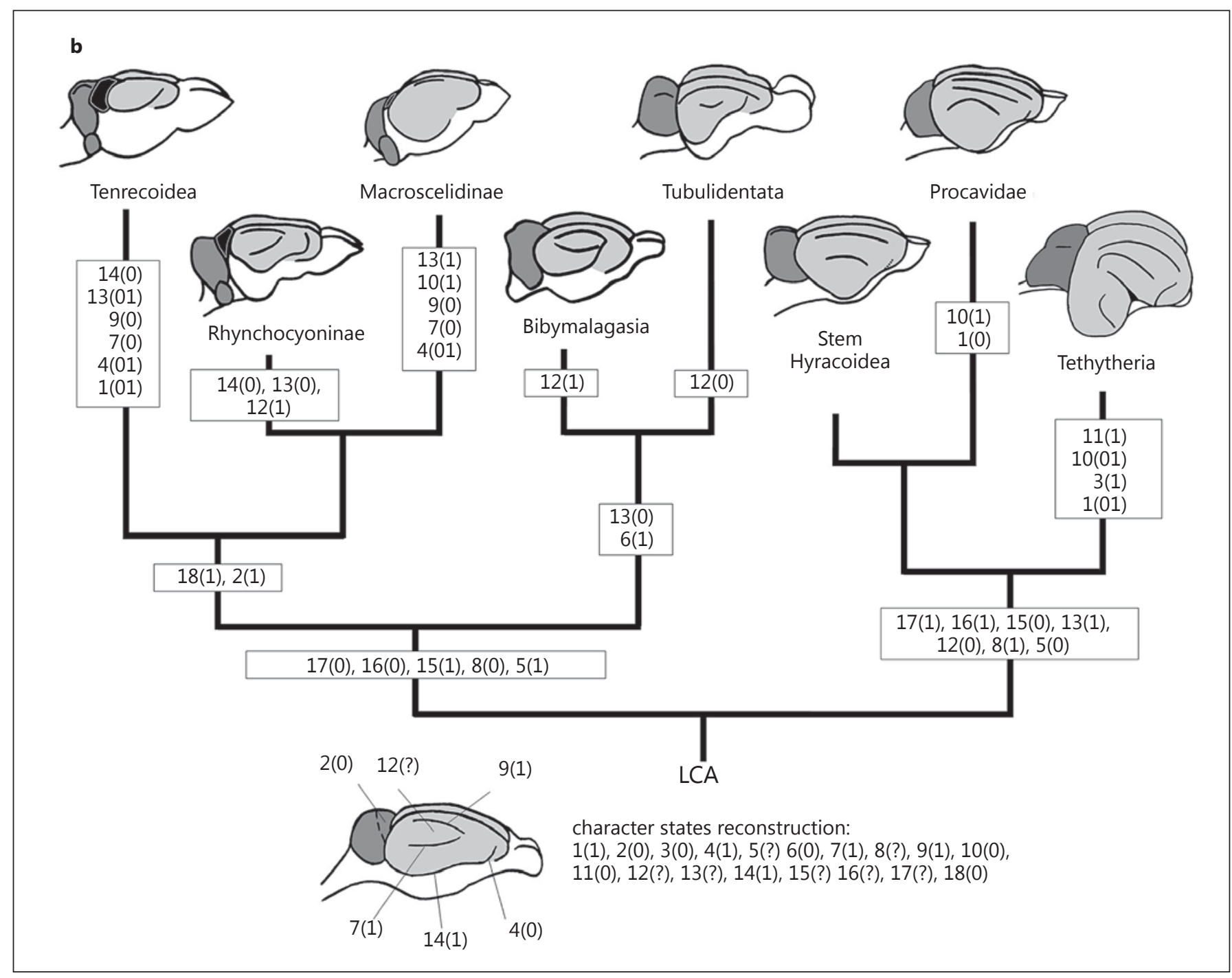

Fig. 3. Reconstruction of the endocranial morphology of the LCA of afrotherians. b Discrete character states reconstruction of brain traits across Afrotheria and reconstruction of the LCA brain. The neopallium is in light grey, the midbrain is in black and the cerebellum is in dark grey. Drawings are not to scale to emphasize on morphological comparison. Character changes are displayed along branches (see table 2 for the character list).

dorsally [Elliot Smith, 1902]. Macroscelidinae are unique regarding this dorsal exposure of the intercalary sulcus. According to Le Gros Clark [1928], it is due to the hypertrophy of the retrosplenial area which draws the cingulate gyrus onto the dorsal aspect of the brain. This phenomenon is also called 'pronation of the hemisphere' [Edinger, 1948].

The neopallium of Rhynchocyon differs from that of other Macroscelididae and from other Afroinsectivora in having three distinct and clearly visible neopallial sulci (fig. 2e). One of them is short and located rostroventral- ly while the remaining others are longer and define an almond-shaped gyrus as in Plesiorycteropus (fig. 2e). The homology of these sulci is yet to be ascertained. It is possible that one of these sulci could be homologous to the intercalary sulcus of Macroscelidinae. If this is so, this sulcus should part the retrosplenial area (cingulate gyrus) from the visual area (lateral gyrus) on the dorsal aspect of the neocortex, as in Macroscelides and Elephantulus [Le Gros Clark, 1928]. Le Gros Clark [1932] briefly described the brain of Rhynchocyon but did not discuss the homology of these sulci. However, he mentioned that 
the retrosplenial area is less developed in Rhynchocyoninae with respect to that of Macroscelidinae. Thus, it seems unlikely that the intercalary sulcus migrates on the dorsal face of the neopallium due to the lack of the hypertrophy of the retrosplenial area in Rhynchocyon. On the other hand, the two dorsal-most sulci of Rhynchocyon are topologically very similar to the sulcus lateralis and the suprasylvia present in Plesiorycteropus (see above) and may correspond to these sulci. The homology of the rostroventral sulcus in Rhynchocyon is also disputable. Le Gros Clark [1932] homologized it to the orbital excavation he identified earlier in Elephantulus and Macroscelides. However, in Petrodromus, the orbital excavation is accompanied by a preasylvia rostrally, which closely resembles the rostroventral sulcus of Rhynchocyon (fig. 2e, f). It is a short sulcus that extends from the posterior rhinal fissure, whereas the orbital excavation of Elephantulus and Macroscelides is a wide and shallow depression located more caudolaterally. Thus, it seems that there is no orbital excavation in Rhynchocyon, but a preasylvia instead.

\section{Tethytheria and Hyracoidea (Paenungulata)}

Extant Paenungulata are the more encephalized representatives of Afrotheria but their oldest extinct representatives display low EQ values, especially Moeritherium and Seggeurius $(\mathrm{EQ}=0.2$ ), which implies a convergent evolution of encephalization in Hyracoidea and Proboscidea (fig. 3a; table 3). Hyracoidea is the first diverging order of Paenungulata (fig. 3a). Extant and extinct hyracoids have a quadrangular-shaped neopallium in dorsal view (fig. 2c, d). The neopallium is also strongly expanded laterally (microsmatic). There is a deep sylvian fossa that defines a prominent temporal lobe, as in Tethytheria [Andrews, 1906; Friant, 1957; Dechaseaux, 1962].

The Procaviidae are characterised by the small size of their cerebellum and olfactory bulbs (table 1) resulting in a curved arrangement of the brain. The EQ is usually high (table 1; online suppl. data 3), but the Quaternary species Procavia transvaalensis, for which brain size approximates that of extant species [Wells, 1939] and body size was 50\% larger [Rasmussen and Gutierrez, 2010], must have been consequently less encephalized. In Procavidae, there is a splenial (or intercalary) sulcus on the medialmost aspect of the neopallium. A sulcus coronolateralis is also present in all genera but it is divided into a sulcus coronalis, a sulcus lateralis and a sulcus cruciatus in Procavia [Elliot Smith, 1902; Edinger, 1948; Friant, 1957]. The praesylvia is always present but sometimes shallow. It always contacts the anterior rhinal fissure. The supra-
Table 3. Character states reconstruction at nodes (see fig. 3a)

\begin{tabular}{lclll}
\hline Clade & Node & $\begin{array}{l}\text { Neo/Rhin } \\
\text { ratio }\end{array}$ & EQ1 & EQ2 \\
& & 2.96 & 0.60 & 0.54 \\
Afrotheria (LCA) & 1 & NA & 0.64 & 0.55 \\
Paenungulata & 2 & 3.87 & 0.55 & 0.52 \\
Hyracoidea & 3 & 5.55 & 0.82 & 0.81 \\
Procavidae & 4 & NA & 0.76 & 0.58 \\
Tethytheria & 5 & NA & 0.76 & 0.2 \\
Proboscidea & 6 & NA & 1.31 & NA \\
Elephantimorpha & 7 & NA & 1.68 & NA \\
Elephantidae & 8 & NA & 0.49 & 0.42 \\
Sirenia & 9 & NA & 0.37 & 0.33 \\
& 10 & 2.05 & 0.55 & 0.53 \\
Afroinsectiphilia & 11 & 1.79 & 0.47 & 0.46 \\
& 12 & 1.95 & 0.45 & 0.45 \\
Tubulidentata & 13 & 1.39 & 0.60 & 0.58 \\
Afroinsectivora & 14 & 1.37 & 0.70 & 0.69 \\
Macroscelididae & 15 & 1.10 & 0.74 & 0.73 \\
Rhynchocyoninae & 16 & 1.61 & 0.75 & 0.75 \\
Macroscelidinae & 17 & 1.36 & 0.8 & 0.79 \\
& 18 & 0.76 & 0.54 & 0.53 \\
Tenrecoidea & 19 & 0.36 & 0.53 & 0.53 \\
Chrysochloridae & 20 & 0.52 & 0.49 & 0.48 \\
Tenrecidae & 21 & 0.40 & 0.50 & 0.50 \\
Potamogalinae & 22 & 0.42 & 0.44 & 0.43 \\
Malagasy tenrecs & 23 & 0.28 & 0.36 & 0.36 \\
Tenrecinae & 24 & 0.45 & 0.45 & 0.45 \\
Oryzorictinae & 25 & & & \\
\hline
\end{tabular}

EQ1 is the encephalization quotient reconstructed after the analysis performed on the full dataset and EQ2 is that excluding Elephantimorpha and extant Sirenia.

sylvia is arched. The ectosylvia is not typically present in Procaviidae as it is only variably present in extant and extinct Procavia [Elliot Smith, 1902; Wells, 1939], absent or faint in Heterohyrax [Wells, 1939; Fischer, 1992] and absent in Dendrohyrax [Friant, 1957; this study]. The floccular lobes of the cerebellum are not prominent, as in Orycteropus, Plesiorycteropus and Tethytheria.

The endocranial cast of Paleogene hyracoids is small with respect to the skull while it is bigger in extant genera [Meyer, 1978; Rasmussen, 1989] (fig. 4a, b). The brain was linearly arranged as demonstrated by the morphology of Seggeurius (fig. 4c). Olfactory bulbs are pedunculated in Saghatherium (fig. 2d). It is impossible to say whether the midbrain was dorsally exposed or not on either specimen. The telencephalon, even though it is microsmatic, displays a less laterally expanded neopallium than in extant forms (table 1). On the neopallium of Saghatherium (the best preserved), the praesylvia is not clearly present, but 
Fig. 4. CT reconstruction of the endocranial cast of various Paenungulata. a, b Endocranium of Saghatherium and Procavia (Hyracoidea) within the skull in transparent. c, d Annotated endocranium of the Eocene genera Seggeurius (Hyracoidea) and Prorastomus (Sirenia), showing the serial organisation of the brain with comparison to Heterohyrax (d). Cb. = Cerebellum; Neo. = neopallium; O.b. = olfactory bulb; Rh.f. = rhinal fissure; Sy.fs. = sylvian fossa; S.lat. = sulcus lateralis; Supras. = suprasylvia; Tp.l. = temporal lobe; Trig.n. = trigeminal nerve. Scale bar $=10 \mathrm{~mm}$.

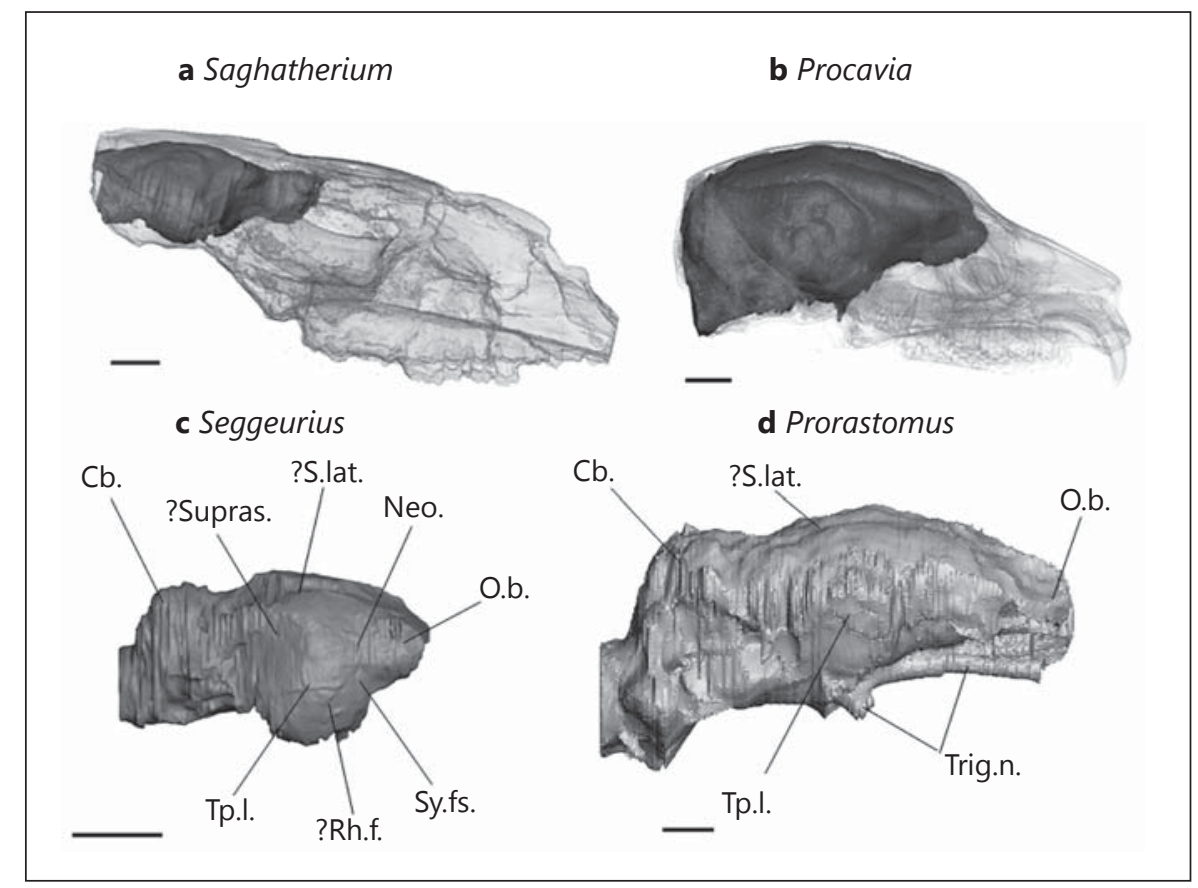

this situation could be due to the poor quality of the specimen. Thus, there are only two visible sulci on the neopallium in Saghatherium (fig. 2c, d). The more lateral sulcus is ventrally arched, as are the suprasylvia of procavids and tethytheres. The most dorso-medial one is longer and rectilinear. It does not correspond to the splenial sulcus of extant Procaviidae because it runs parallel to the sagittal sinus, while the splenial sulcus runs obliquely (fig. 2c, d).

The brain of Tethytheria is strongly flexed anteroposteriorly, resulting in a non-linear organisation of its components [Friant, 1957]. However, Edinger [1933] has established that the endocranial casts of Paleogene sirenians were not strongly curved (fig. $4 \mathrm{~d}$ ), which testifies that the brain stem of Tethytheria (and probably Paenungulata) could have been primitively more linearly arranged. The midbrain is never exposed. The olfactory bulbs are very small in extant sirenians, which reflect the reduction of the sense of smell through their adaptation to life underwater [Pirlot and Kamiya, 1985; Reep et al., 2007]. In Prorastomus, a stem sea cow, the olfactory bulbs are still large (table 1) but the trigeminal nerves are also large (fig. 4d), as in extant Dugong and most aquatic mammals, suggesting intensive snout sensory perception [Bauchot and Heinz, 1968; Pirlot and Kamiya, 1985]. The EQ tends to decrease in Sirenia (fig. 3a; table 3), but it can exceed the value of 1 in Arsinoitherium (EQ = 1.17) and Elephantimorpha (reconstructed ancestral $\mathrm{EQ}=1.31$; table 3 ). In mammals the brain is covered by a thin layer of veinous sinuses and white mater called the meninx. The layer of meninx is usually so thin that it does not introduce a significant bias between the true morphology of the neopallium and that observed on its endocast [Dechaseaux, 1962; Bauchot and Stephan, 1967]. However, in Tethytheria the meninges are very thick and form a rete mirabile [Dechaseaux, 1958a; Shoshani et al., 2006; Manger, 2010]. This layer of meninx is so thick in extant tethytheres that it obliterates the sulcal pattern of the neopallium which results in a lissencephalic aspect of the endocranial cast [Edinger, 1933; Dechaseaux, 1958a, 1962]. The only sulcus observable on the endocast of the neopallium in extant Tethytheria is the deep pseudosylvia, which defines a hypertrophied temporal lobe [Edinger, 1933; Dechaseaux, 1958a]. This pattern is also observable on the endocranial cast of fossil tethytheres (e.g. Mammuthus, Moeritherium, Arsinoitherium, Eotheroides and Desmostylus) suggesting that a comparably thick layer of meninx was already present at the root of the tethytherian clade [Andrews, 1906; Edinger, 1933; Dechaseaux, 1958a, 1962; Edinger, 1975; Thewissen and Domming, 1992].

Under the layer of meninx, the neopallium of extant elephants (Elephas and Loxodonta) is densely sulcated. Past workers have recognized a deep sylvian fossa, an arched suprasylvia and a coronolateral (or lateral) sulcus, just as in Hyracoidea, but failed to identify a splenial sul- 
cus in most cases [Elliot Smith, 1902; Friant, 1954a, b, 1957; Anthony, 1972; Cozzi et al., 2001; Shoshani et al., 2006]. In addition they found a sylvian fossa prolongated dorsally by a deep pseudosylvia, a praesylvian sulcus starting from the anterior rhinal fissure and bearing three ramifications, a transverse sulcus called the fissure of Rolando, an antero-temporal sulcus called the postsylvia and a postero-temporal sulcus called the sulcus postlateral. In sirenians, the brain seems lissencephalic at first sight [Elliot Smith, 1902; Friant, 1954b; Pirlot and Kamiya, 1985], but according to Anthony [1972], Ronald et al. [1978] and Welker [1990], shallow sulci are observable on the brain. These last three studies recognized the same ramified praesylvia, a fissure of Rolando, two dorsal sulci (sulcus lateralis and suprasylvia), a putative splenial sulcus and two posterior sulci (postsylvia and postlateral) as in elephants, which suggests a secondary loss of the sulcal pattern.

\section{Discussion}

The Ancestral Brain Morphology of Afrotherians

The new data provided here shows that the endocrania of many afrotherian mammals display advanced characters. Rhynchocyon displays a complex sulcal pattern of the neopallium with two sulci that are absent in all other sicsmacroscelides (suprasylvia and sulcus lateralis) and one more, which is also present in Petrodromus (praesylvia; fig. 2e). Such a fissured neopallium evocates the morphology of Orycteropus and Plesiorycteropus (fig. 2a, b). Given the basal branching of Macroscelididae, Tubulidentata and Bibymalagasia in the phylogenetic tree of Afroinsectiphilia [Asher et al., 2003; Springer et al., 2004; Beck et al., 2006; Poulakakis and Stamatakis, 2010; Kuntner et al., 2011] the complex sulcal pattern encountered in Rhynchocyon, Orycteropus and Plesiorycteropus is reconstructed as plesiomorphic for Afrotheria in our analysis (fig. 3b). Moreover, the brain of Macroscelididae resembles those of Orycteropus and Plesiorycteropus in having a Neo/Rhin ratio which equals or exceeds 1 (table 1 ). The Neo/Rhin ratio is reconstructed as having a value of 2.96 , which means the neopallium was more expanded than the rhinencephalon on the lateral face of the brain in the LCA of afrotherians (table 3). This implies that the endocranial cast of stem-afroinsectipilians was probably more microsmatic and more convoluted (including three sulci) than in extant Tenrecoidea and Macroscelidinae, and was probably morphologically closer to that of early Paenungulata.

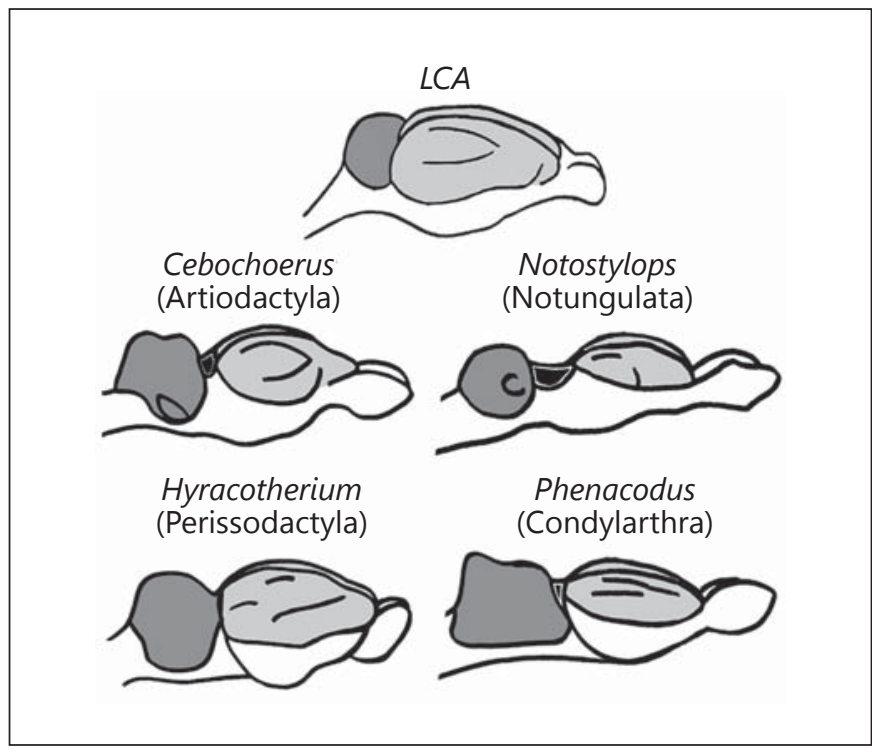

Fig. 5. Reconstructed endocranial cast of the LCA of afrotherians in dorsolateral view, compared to that of various primitive 'ungulates' [redrawn after Edinger, 1956; dechaseaux, 1958b, c, 1974; Radinsky, 1976b; Orliac et al., 2012]. The neopallium is light grey, the midbrain is black and the cerebellum is dark grey. Drawings are not to scale to emphasize morphological comparison.

Consequently, we have re-evaluated the ancestral morphology of the LCA of afrotherians using Mesquite 6.4 software (fig. 3a, b; table 3 ). The following characters have been unambiguously reconstructed as plesiomorphic character for afrotherians: the straight arrangement of the brain (character 1, also present in Rhynchocyoninae, Tubulidentata, Bybimalagasia and Paenungulata), the absence of midbrain exposure (character 2, though the polarity of this character could not be ascertained with confidence in stem hyracoids), the presence of the three neopallial sulci encountered in the genera described above [praesylvia (character 4), suprasylvia (character 7) and sulcus lateralis (character 8)], the absence of an intercalary (or splenial) sulcus (character 9, the pronation of the hemisphere occurs in Procaviidae and Macroscelidinae only), a ventrally expanded neopallium that covers more than $50 \%$ of the lateral face of the brain (character 14) and the absence of prominent floccular lobes. Interestingly, the sulcus lateralis and the suprasylvia may have defined an almond-shaped gyrus, as encountered in Rhynchocyon and Plesiorycteropus (character 12, ambiguous). States of the characters 5, 8,13,15, 16 and 17 are also ambiguous at the root of the tree, but their presence in the LCA of afrotherians seems unlikely because they are de- 
rived in Paenungulata or Afroinsectiphilia only and must be synapomorphic for these clades. The value of the reconstructed EQ is comprised between 0.54 and 0.60 (table 3).

\section{An Ungulate-Like Ancestor}

Before the discovery of the afrotherian clade, nearly all afrotherian orders had been more-or-less assimilated into one or another group of hoofed mammals. The paenungulates were the first [Gregory, 1910], and they were followed by some afroinsectiphilians such as the tubulidentates [Sonntag and Woollard, 1925; Shoshani and McKenna, 1998], the bibymalagasian [MacPhee, 1994] and the macroscelides [Frechkop, 1931; Hartenberger, 1986; Simons et al., 1991]. The hypothesis nesting Macroscelidea within condylarthrans (archaic ungulates) retains support within the literature [Tabuce et al., 2007; Holroyd and Mussell, 2005; Zack et al., 2005; Penkrot et al., 2008]. Moreover, since the discovery of the afrotherian clade, some authors argued in favour of an ungulatelike afrotherian LCA because typical ungulate features are shared between Paenungulata, Macroscelidea and Tubulidentata (e.g. squared cheek teeth, cursoriality, presence of a cotylar fossa of the astragalus) [Seiffert, 2002, 2003; Robinson and Seiffert, 2004; Tabuce et al., 2007; Asher and Seiffert, 2010]. These elements strongly suggest that the body plan of the LCA of afrotherians could have been ungulate-like, whereas most lineages of Placentalia are consensually thought to descend from insectivore-like mammals [Asher, 2005].

As stated above, the endocranial morphology of hoofed mammals is distinctly more advanced than the ancestral morphotype for Eutheria. The ventrolaterally expanded neopallium, the folded neopallium, the absence of voluminous flocullar lobe and the absence of midbrain exposure, which are here reconstructed in the LCA of afrotherians, are typically present in modern ungulates (Ferungulata and Paenungulata) [Elliot Smith, 1902; Edinger, 1948; Dechaseaux, 1962; Nieuwenhuys et al., 1998]. Regardless to the homology of the neopallial sulci, the endocranial morphology of the LCA of afrotherians equals or exceeds in complexity that of many early Tertiary hoofed mammals such as condylarthrans (e.g. Phenacodus) [Edinger, 1948, 1956; Dechaseaux, 1958b; Radinsky, 1976a; Orliac et al., 2012], Diacodexis and most Eocene Artiodactyla [Dechaseaux, 1970, 1974; Sigogneau-Russell and Russell, 1983], the stem Perissodactyla Hyracotherium [Radinsky, 1976b] and the stem Notungulata Notostylops [Dechaseaux, 1958c; Radinsky, 1981] (fig. 5). In addition, the EQ of the LCA of afrotherians is greater than that of the most encephalized Paleogene ungulates [Jerison, 1973] which underlines its advanced morphology. Finally, the almond-shaped suprasylvian gyrus defined by the two dorsal sulci observed in Rhynchocyon and Plesiorycteropus, and ambiguously reconstructed in the LCA of afrotherians, strikingly resembles what can be observed in Eocene artiodactyls [Dechaseaux, 1970, 1974; Sigogneau-Russell and Russell, 1983] (fig. 5). To conclude, despite showing some 'primitive' traits (e.g. serial brain, praesylvia extending from the posterior rhinal fissure, $a b-$ sence of splenial sulcus), the LCA of afrotherians shares noticeable endocranial similarities with hoofed mammals which argues in favour of an ungulate-like ancestral body plan for afrotherians.

\section{The Evolution of the Brain in Afroinsectivora}

It was long thought that the linear arrangement of the brain, the smooth aspect of the neopallium and the huge midbrain exposure encountered in the brains of Tenrecoidea and Macroscelidinae were plesiomorphic features of the mammalian brain retained from the ancestral eutherian condition (more specifically, the brain of Tenrec with its reduced neocortex has long been considered as the most archaic mammalian brain) [Le Gros Clark, 1932; Edinger, 1948, 1956; Jerison, 1973; Kielan-Jaworowska, 1986; Nieuwenhuys et al., 1998]. Nonetheless, following the new scenario of an advanced brain in the LCA of afrotherians, the a priori 'primitive' morphology of the brain of some Afroinsectivora would have been acquired secondarily and convergently in Tenrecoidea and Macroscelidinae.

If the brain of Afroinsectivora evolved from a primitively folded and gyred brain, what kind of mechanism could trigger the loss of this neopallial complexity? Some authors found a correlation between absolute brain size and the overall brain morphology: as the brain gets bigger, the telencephalon expands causing the cortex to fold, the midbrain being covered resulting in it looking consequently curved rather than straight [Finlay et al., 2001; Reep et al., 2007]. More specifically, a correlation between the complexity of the neopallial sulcal pattern and the absolute brain size has long been observed across closely related mammals [Edinger, 1956; Radinsky, 1976a; Welker, 1990]. Though not perfect [Radinsky, 1976a; Welker, 1990], this correlation implies that within a clade, animals with bigger brains tend to have more convoluted neocortex than those with smaller ones because the expansion of the cortical sheet outpaces the endocranial volume, generating an intracranial mechanical tension and resulting in the folding of the cortical sheet [Van Essen, 1997]. In 
this regard, if the complexity of the sulcal pattern and the size of the telencephalon are inversely correlated to brain size, one could expect the reduction of brain and probably body sizes during the afroinsectivoran evolution. The fossil record of early Afroinsectivora is so far relatively poor, but to date no paleontological clues argue in the favour of a reduction of brain or body sizes in Afroinsectivora [Seiffert et al., 2007; Tabuce et al., 2007, 2008]. However, evidence for a reduction of the absolute body size during afroinsectivoran's evolution has been provided indirectly through the discovery of an increase of the third codon position GC-content during Tenrec evolution [Romiguier et al., 2013]. Moreover, in tenrecs, developmental studies have shown that the cerebral hemispheres were not primitively reduced, but that their small size was acquired secondarily [Elliot Smith, 1902]. If such a decrease in the size of the brain and body mass really occurred, it could have triggered the relaxation of the endocranial constraint and led to the loss of the neopallial folding and other advanced brain traits, at least in Tenrecoidea.

In addition to the simple neopallial sulcal pattern, the midbrain exposure is another 'primitive' feature shared by Tenrecoidea and the subfamily Macroscelidinae. Indeed, afroinsectivorans display a huge exposure of the corpora quadrigemini (midbrain), though this is not homologous between the orders Chrysochloridae, Tenrecidae and Macroscelididae. While in Macroscelididae the anterior corpus quadrigemina is the greater, in Tenrecoidea the posterior one is the greater [Le Gros Clark, 1932; Stephan and Bauchot, 1960; Bauchot and Stephan, 1967]. In Chrysochloridae the posterior (auditive) corpus quadrigemina is the greater because of the reduction of the anterior (visual). This pattern is surely linked to the atrophy of eyes in golden moles [Stephan and Bauchot, 1960]. In Tenrecidae the anterior corpus quadrigemina is normal but the posterior one is hypertrophied, potentially for echolocation [Gould, 1965; Bauchot and Stephan, 1967], as it occurs in bats [Edinger, 1964; Dechaseaux, 1967]. Finally, in Macroscelididae, the midbrain exposure is made by the hypertrophied anterior corpus quadrigemina, a morphology that could be linked to their peculiar visual capacities [Dengler-Crish et al., 2006]. The scenario of a convergent acquisition of the midbrain exposure constrained by functional and adaptive requirements fits more parsimoniously with these observations than that involving the retention of the 'primitive' midbrain exposure.

\section{Implications on Divergence Time Estimation}

The time of origin of Afrotheria is likely to be late Cretaceous in age according to molecular clocks [Douady and Douzery, 2003; Bininda-Emonds et al., 2007; Poulakakis and Stamatakis, 2010], but no fossil afrotherian is known until the late Paleocene, which argues in the favour of an origin after the Cretaceous/Paleogene boundary [Gheerbrant et al., 2005; Gheerbrant, 2009]. The 'poor fossil record' of basal afrotherians is often cited as an argument by molecular biologists to validate the Cretaceous age of divergence of Afrotheria that they estimate [Poulakakis and Stamatakis, 2010]. However, although the Cretaceous mammalian record in Africa is admittedly poor, data for this time and place do exist, documenting, for example, the absence of eutherians in the 'middle' Cretaceous of Morocco [Sigogneau-Russell et al., 1988].

The reconstructed ancestral morphology of the afrotherian brain looks clearly more advanced than that of some early Paleogene species (fig. 5). So, on one hand, one could argue that this advanced condition strengthens a post-Cretaceous origin for Afrotheria contrary to what molecular estimates suggest [Douady and Douzery, 2003; Bininda-Emonds et al., 2007; Poulakakis and Stamatakis, 2010]. On the other hand, given our admittedly poor knowledge of mammalian evolution during the Cretaceous in Africa, the hypothesis of the occurrence in that continent of a Cretaceous ungulate-like LCA of afrotherians could not be rejected. Nevertheless, the worldwide earliest known putative archaic ungulates may have occurred as late as the latest Cretaceous, only 300,000 years before the K/P boundary, and their belonging to Placentalia is not ascertain [Prasad et al., 2007; Archibald et al., 2011]. As a consequence, a post-Cretaceous origin for Afrotheria fits more parsimoniously with the current fossil record and our data.

Finally, our reconstruction of ancestral brain traits emphasizes many changes in brain size across afrotherian phylogeny (fig. 3a). The EQ tend to decrease across Sirenia, the (Tubulidentata, Bibymalagasia) clade and Tenrecoidea, especially in the (Tenrec, Hemicentetes, Setifer, Echinops) clade, and tend to increase in Macroscelididae, Proboscidea and Hyracoidea (table 3). Recent work has suggested that molecular ages of divergence in Primates may have been overestimated because modern rates of mutations are not representative of ancient mutation rates [Steiper and Seiffert, 2012]. These authors propose to re-calibrate molecular clocks using life-history traits such as brain size, which are tightly correlated to mutation rates. They found that taking such life-history traits into account, the estimations of divergence ages in Primates evolution move forward from the late Cretaceous to the early Paleogene, primarily because early representatives of Primates were less encephalized than their mod- 
ern counterparts. Given the huge changes in brain size and EQ across afrotherians phylogeny as reconstructed here, one could expect the divergence age of Afrotheria to look very different when taking brain size into account.

\section{Concluding Remarks}

According to Robinson and Seiffert [2004] the long evolution of Afrotheria 'erased' their morphological synapomorphies and removes many morphological clues that could be useful to reconstruct the morphology of their last common ancestor. Our observations reveal that despite some plesiomorphic traits, the morphology of the endocranial cast of the LCA of afrotherians was more advanced than that of any Cretaceous mammal known to date. Its endocranial morphology is even reminiscent of that of some early Cenozoic ungulates. To determine if the progressive aspect of the brain of the LCA of afrotherians (and especially its sulcal pattern) constitute a shared derived trait of Afrotheria is to date impossible in the absence of a clear phylogenetic background. Indeed, both molecular and morphological characters fail in determining the sister-group of Afrotheria, even though close relationships to xenarthrans and/or some condylarths are consensually reported [Springer et al., 2004; Tabuce et al., 2008]. Many authors have argued for a close relationship between two families of hyopsodontid condylarths Louisinidae and Apheliscidae, and some afrotherian orders such as the proboscideans [Gheerbrant, 2009], hyracoids [Godinot et al., 1996] and macroscelides [Hartenberger, 1986; Zack et al., 2005; Tabuce et al., 2007; Penkrot et al., 2008]. These assertions are mainly based on dental and pedal morphology, especially the shared presence of a cotylar fossa of the astragalus [Zack et al., 2005; Tabuce et al., 2007]. To date, no endocrania of either Louisinidae or Apheliscidae have been described. Otherwise, there exists a great variety of neopallial sulcal pattern among xenarthrans ranging from lissencephalic to gyrencephalic brain anatomy [Elliot Smith, 1899, 1902; Anthony, 1972]. Future studies of the endocranial casts of the early representatives of these taxa will allow workers to test their apparent affinities to Afrotheria and to determine whether the advanced morphology of the LCA endocast is a synapomorphy of Afrotheria.

\section{Acknowledgements}

We thank the teams of the medical imaging stations of the $\mathrm{CHU}$ Lapeyronie (Montpellier, France) and Clinique du Parc (Castelnau-le-Lez, France) for their assistance. Montpellier Rio Imaging is thanked for providing access to the Skyscan 1076 Micro-CT engine. We thank N. Karjilov and A. Hilger (Helmholtz-Zentrum, Berlin), and P. Hornberger (Intercontec, Niederwinkling) for their assistance during micro-CT scanning. N. Lange and O. Hampe from the Museum für Naturkunde (Berlin) and R. Ziegler (Natural History Museum, Stuttgart) are also thanked for providing access to specimens. M. Herbin and the team of the Mammifères et Oiseaux collections of the Museum d'histoire naturelle de Paris are thanked. We thank L. Costeur from the Naturhistorisches Museum Basel and A. Currant and L. Howard from the British Museum of Natural History for the scans they kindly provided. We also thank M. Vianey-Liaud (Institut des sciences de l'évolution, Montpellier), M. Orliac (Institut des sciences de l'évolution, Montpellier), T. Lehmann (Forschungsinstitut und Naturmuseum, Senckenberg) and E. Gilissen (Université Libre de Bruxelles, Belgium) for kindly providing advice on this research, as well as A.-L. Charruault (Institut des sciences de l'évolution, Montpellier) and S. Vrard. Financial support came from the ANR-08-JCJC0017-PALASIAFRICA program.

\section{References}

Andrews CW (1906): A Descriptive Catalogue of the Tertiary Vertebrata of Fayum, Egypt. British Museum (Natural History), London.

Anthony J (1972): Le nevrax des mammifères; in Grasse PP (ed): Anatomie, Systématique, Biologie. Masson, Mammifères, vol 16, pp 1275.

-Archibald JD, Zhang Y, Harper T, Cifelli RL (2011): Protungulatum, confirmed Cretaceous occurrence of an otherwise Paleocene eutherian (placental?) mammal. J Mam Evol $18: 153-161$.
Asher RJ (2005): 'Insectivoran-grade Placentals'; in Rose KD, Archibald JD (eds): The Rise of Placental Mammals: Origins and Relationships of the Major Extant Clades. Baltimore, Johns Hopkins University Press, pp 50-70.

-Asher RJ (2007): A database of morphological characters and a combined-data reanalysis of placental mammal phylogeny. BMC Evol Biol 7:108.

Asher RJ, Helgen KM (2010): Nomenclature and placental mammal phylogeny. BMC Evol Biol 10:102.
Asher RJ, Novacek MJ, Geisler JG (2003): Relationships of endemic African mammals and their fossil relatives based on morphological and molecular evidence. J Mam Evol 10:131194.

Asher RJ, Seiffert ER (2010): Systematics of endemic African mammals; in Werdelin L, Sanders WJ (eds): Cenozoic Mammals of Africa. Berkeley, University of California Press, pp 903-920.

Bauchot R, Heinz S (1968): Étude des modifications encéphaliques observées chez les insectivores adaptés à la recherche de nourriture en milieu aquatique. Mammalia 32:228-275. 
Bauchot R, Stephan H (1967): Encephales et moulages endocraniens de quelques insectivores et primates actuels. Coll Int CNRS 163:575-587.

-Bauchot R, Stephan H (1970): Morphologie comparée de l'encéphale des insectivores tenrecidae. Mammalia 34:514-541.

-Beck R, Bininda-Emonds ORP, Cardillo M, Liu FR, Purvis A (2006): A higher-level MRP supertree of placental mammals. BMC Evol Biol 93:1-14.

Benoit J, Orliac M, Tabuce R (2013): The petrosal of Chambius (Macroscelidea Afrotheria) from the Eocene of Djebel Chambi (Tunisia). J Syst Paleontol, in press.

-Bininda-Emonds ORP, Cardillo M, Jones KE, MacPhee RDE, Beck R, Grenyer R, Price SA, Vos RA, Gittleman JL, Purvis A (2007): The delayed rise of present-day mammals. Nature 446:507-511.

Boddy AM, McGowen MR, Sherwood CC, Grossman LI, Goodman M, Wilman DE (2012): Comparative analysis of encephalization in mammals reveals relaxed constraints on anthropoid primate and cetacean brain scaling. J Evol Biol 25:981-994.

Corbet GB (1995): A cladistic look at classification within the subfamily Macroscelidinae based upon morphology. Mammal Rev 25:15-18.

Court N, Mahboubi M (1993): Reassessment of Lower Eocene Seggeurius amourensis - aspects of primitive dental morphology in the mammalian order Hyracoidea. J Paleontol 67: 889-893.

Cozzi B, Spagnoli S, Bruno L (2001): An overview of the central nervous system of the elephant through a critical appraisal of the literature published in the XIX and XX centuries. Brain Res Bull 54:219-227.

Dechaseaux C (1958a): L'encéphale d'Elephas meridionalis. Ann Paléontol 64:269-278.

Dechaseaux C (1958b): Encéphales de Notongulés; in Piveteau J (ed): Traité de Paléontologie. Paris, Masson et Cie, vol 6, pp 121-129.

Dechaseaux C (1958c): Encéphales de Condylarthres; in Piveteau J (ed): Traité de Paléontologie. Paris, Masson et Cie, vol 6, pp 28-30.

Dechaseaux C (1962): Cerveaux d'Animaux Disparus. Paris, Masson.

Dechaseaux C (1967): Localisation cérébrales et Paléoneurologie. Coll Int CNRS 163:569-573.

Dechaseaux C (1970): Récents Résultats en Paléoneurologie. Bull Acad et Soc Lorraines Sci 9: 223-232.

Dechaseaux C (1974): Moulages endocraniens d'artiodactyles primitifs-essai sur l'histoire du néopallium. Ann Paléontol 55:195-248.

-Dengler-Crish CM, Crish SD, O'Riain MJ, Catania KC (2006): Organization of the somatosensory cortex in elephant shrews (E. edwardii). Anat Rec A Discov Mol Cell Evol Biol 288:859-866.

Douady CJ, Catzeflis F, Raman J, Springer MS, Stanhope MJ (2003): The Sahara as a vicariant agent, and the role of Miocene climatic events, in the diversification of the mammalian order Macroscelidea (elephant shrews)? Proc Nat Acad Sci USA 100:8325-8330.
Douady CJ, Douzery EJP (2003): Molecular estimation of eulipotyphlan divergence times and the evolution of 'Insectivora'. Mol Phylogenet Evol 28:285-296.

Edinger T (1933): Über Gehirne tertiärer Sirenia Ägyptens und Mitteleuropas sowie der rezenten Seekühe. Abh Bayer Akad Wiss 20:5-36.

Edinger T (1939): Two notes on the central nervous system of fossil Sirenia. Bulletin of the Faculty of Science, Fouad I University, Cairo, vol 19, pp 43-57.

Edinger T (1948): Evolution of the horse brain. Geol Soc Am Mem 25:1-177.

Edinger T (1956): Objets et Résultats de la Paléoneurologie. Ann Paléontol 62:97-116.

Edinger T (1964): Midbrain exposure and overlap in mammals. Am Zool 4:5-19.

Edinger T (1975): Paleoneurology 1804-1966: an annotated bibliography. Adv Anat Embryol Cel Biol 49:1-258.

Elliot Smith G (1899): The Brain in the Edentata. Trans Linn Soc London Zool 7:277-394.

Elliot Smith G (1902): The brains of the Mammalia. Descriptive and Illustrated Catalogue of the Physiological Series of Comparative Anatomy contained in the Museum of the Royal College of Surgeons of England 2:138-481.

Finlay BL, Darlington RB, Nicastro N (2001): Developmental structure in brain evolution. Behav Brain Sci 24:263-308.

Fischer MS (1992): Hyracoidea. Handbuch der Zoologie 8:1-169.

Frechkop S (1931): Notes sur les Mammifères. V. Note préliminaire sur la dentition et la position systématique des Macroscelididae. Bull Mus R Hist Nat Belgique 7:1-11.

Friant M (1954a): Les principales caractéristiques du cerveau des ordres actuels d'ongulés Ungulata sensu lato: Proboscidea, Hyracoidea, Perissodactyla, Artiodactyla, Sirenia. CR Acad Sci II 239:1004-1006.

Friant M (1954b): Le cerveau du lamantin (Manatus inunguis Natterer). Vierteljahresschrift Naturf Ges Zürich 99:129-135.

Friant M (1957): Morphologie et développement du cerveau des mammifères euthériens. III. Série des ongulés. Ann Soc Zool Belgique 88: 321-367.

Friant M (1960): Morphologie et développement du cerveau des mammifères eutheriens IV, Séries des Rongeurs, des Pangolins et de l'Oryctérope. Ann Soc Zool Belgique 89:365-394.

Furusawa H (2004): A phylogeny of the North $\mathrm{Pa}$ cific Sirenia (Dugongidae: Hydrodamalinae) based on a comparative study of endocranial casts. Paeontol Res 8:91-98.

Gheerbrant E (2009): Paleocene emergence of elephant relatives and the rapid radiation of African ungulates. Proc Nat Acad Sci 106: 10717-10721.

Gheerbrant E, Domning D, Tassy P (2005): Paenungulata (Sirenia, Proboscidea, Hyracoidea, and relatives); in Rose KD, Archibald JD (eds): The Rise of Placental Mammals: Origins and Relationships of the Major Extant Clades. Baltimore, John Hopkins University Press, pp 84-105.
Godinot M, Smith T, Smith R (1996): Mode de vie et affinités de Paschatherium (Condylarthra, Hyopsodontidae) d'après ses os du tarse; in Godinot M, Gingerich PD (eds): Paléobiologie et Évolution des Mammifères Paléogènes: Volume Jubilaire en Hommage à Donald E. Russell. Palaeovertebrata 25:225-242.

Gould E (1965): Evidence for echolocation in the Tenrecidae of Madagascar. Proc Am Philos Soc 109:352-360.

Gregory WK (1910): The orders of mammals. Bull Am Mus Nat Hist 27:1-525.

Hartenberger J-L (1986): Hypothèse paléontologique sur l'origine des Macroscelidea (Mammalia). CR Acad Sci II 302:247-249.

Holroyd PA (2010): Tubulidentata; in Sanders WJ, Werdelin L (eds): Cenozoic Mammals of Africa. Berkeley, University of California Press, pp 10-111.

Holroyd PA, Mussell JC (2005): Origin and relationships of the Macroscelidea and Tubulidentata; in Rose KD, Archibald JD (eds): The Rise of Placental Mammals: Origins and Relationships of the Major Extant Clades. Baltimore, Johns Hopkins University Press, pp 71-83.

Horovitz I (2004): Eutherian mammal systematics and the origins of South American ungulates as based on postcranial osteology. Bull Carnegie Mus Nat Hist 36:63-79.

Jerison HJ (1973): Evolution of the brain and intelligence. New York, Academic Press.

Kemp TS (2005): The Origin and Evolution of Mammals. Oxford, Oxford University Press.

Kielan-Jawarowska Z (1986): Brain evolution in Mesozoic mammals. Contribution to Geology, University of Wyoming, Special Paper 3: 21-34.

Kuntner M, May-Collado LJ, Agnarsson I (2011): Phylogeny and conservation priorities of afrotherian mammals (Afrotheria, Mammalia). Zool Scr 40:1-15.

Le Gros Clark WE (1928): On the brain of the Macroscelididae (Macroscelides and Elephantulus). J Anat London 62:245-275.

Le Gros Clark WE (1932): The Brain of the Insectivora. Proc Zool Soc London 102:975-1013.

Lehmann T (2009): Phylogeny and systematics of the Orycteropodidae (Mammalia, Tubulidentata). Zool J Lin Soc 155:649-702.

MacPhee RDE (1994): Morphology, adaptations, and relationships of Plesiorycteropus, and a diagnosis of a new order of eutherian mammals. Bull Am Mus Nat Hist 220:1-214.

- Macrini TE, Rougier GW, Rowe T (2007): Description of a cranial endocast from the fossil mammal Vincelestes neuquenianus (Theriiformes) and its relevance to the evolution of endocranial characters in therians. Anat Rec 290:875-892.

Maddison WP, Maddison DR (2009): Mesquite: a modular system for evolutionary analysis. Version 2.6. http://mesquiteproject.org.

Mahboubi M, Ameur R, Crochet J-Y, Jaeger J-J (1986): El Kohol (Saharan Atlas, Algeria): a new Eocene mammal locality in Northwestern Africa. Palaeontogr Abt A 192:15-49. 
-Manger PR, Hemingway J, Haagensen M, Gilissen E (2010): Cross-sectional area of the elephant corpus callosum: comparison to other eutherian mammals. Neuroscience 167:815824.

Meyer G (1978): Hyracoidea; in Maglio V, Cooke $\mathrm{H}$ (eds): Evolution of African Mammals. Massachusetts, Harvard University Press, pp 284314.

Nieuwenhuys R, Ten Donkelaar HJ, Nicholson C (1998): The central nervous system of vertebrates. Berlin, Springer.

Novacek MJ (1984): Evolutionary stasis in the elephant-shrew, Rhynchocyon; in Eldredge N, Stanley SM (eds): Living fossils. New-York, Springer, pp 4-22.

Orliac MJ, Argot C, Gilissen E (2012): Digital cranial endocast of Hyopsodus (Mammalia, 'Condylarthra'): a case of paleogene terrestrial echolocation? PLoS One 7:e30000.

O'Shea TJ, Reep RL (1990): Encephalization quotients and life-history traits in the Sirenia. J Mammal 71:534-543.

Owen R (1868): On the Anatomy of Vertebrates: Mammals. London, Longmans, Green and Co., vol III.

Patterson B (1975): The fossil aardvarks (Mammalia: Tubulidentata). Bull Mus Comp Zool 147:186-237.

Penkrot TA, Zack SP, Rose KD, Bloch JI (2008): Postcranial morphology of Apheliscus and Haplomylus (Condylarthra, Apheliscidae): evidence for a Paleocene Holarctic origin of Macroscelidea; in Sargis E, Dagosto M (eds): Mammalian Evolutionary Morphology: A Tribute to Frederick S. Szalay. Dordrecht, Springer, pp 73-106.

Pilleri G (1990): Endocranial cast of Metaxytherium (Mammalia: Sirenia) from the Miocene of Cerro Gordo, Almeria, Spain. Contrib Paleontol Some Tethyan Cetacea Sirenia (Mammalia) 2:103-113.

Pirlot P, Kamiya T (1985): Qualitative and quantitative brain morphology in the Sirenian $\mathrm{Du}$ gong dugong Erxl. J Zool Syst Evol Res 23:147155.

Poulakakis N, Stamatakis A (2010): Recapitulating the evolution of Afrotheria: 57 genes and rare genomic changes (RGCs) consolidate their history. Syst Biodivers 8:395-408.

- Prasad GVR, Verma O, Sahni A, Parmar V, Khosla AA (2007): A Cretaceous hoofed mammal from India. Science 318:937.

Radinsky LB (1976a): The brain of Mesonyx, a Middle Eocene mesonychid condylarth. Fieldiana Geol 33:323-337.

Radinsky LB (1976b): Oldest horse brains: more advanced than previously realized. Science 194:626-627.

Radinsky L (1981): Brain evolution in extinct South American ungulates. Brain Behav Evol 18:169-187.

Rasmussen DT (1989): The evolution of the Hyracoidea: a review of the fossil evidence; in Prothero DR, Schoch RM (eds): The Evolution of Perissodactyls. New York, Clarendon Press, pp 57-78.
Rasmussen DT, Gutierrez M (2010): Hyracoidea; in Sanders WJ, Werdelin L (eds): Cenozoic Mammals of Africa. Berkeley, University of California Press, pp 123-145.

Reep RL, Finlay BL, Darlington RB (2007): The limbic system in mammalian brain evolution. Brain Behav Evol 70:57-70.

Robinson TJ, Seiffert ER (2004): Afrotherian origins and interrelationships: new views and future prospects. Curr Top Dev Biol 63:37-60.

Romiguier J, Ranwez V, Douzery EJP, Galtier N (2013): Genomic evidence for large, longlived ancestors to placental mammals. Mol Biol Evol 30:5-13.

Ronald K, Selley LJ, Amoroso EC (1978): Biological Synopsis of the Manatee. Ottawa, International Development Research Centre.

Rowe TB, Macrini TE, Luo Z-X (2011): Fossil evidence on origin of the mammalian brain. Science 332:955-957.

Seiffert ER (2002): The reality of afrotherian monophyly, and some of its implications for the evolution and conservation of Afro-Arabia's endemic placental mammals. Afrotherian Conserv 1:3-6.

Seiffert ER (2003): A Phylogenetic Analysis of Living and Extinct Afrotherian Placentals. Durham, Duke University.

-Seiffert ER (2007): A new estimate of afrotherian phylogeny based on simultaneous analysis of genomic, morphological, and fossil evidence. BMC Evol Biol 7:224.

Seiffert ER, Simons EL, Ryan TM, Brown TM, At tia Y (2007): New remains of Eocene and Oligocene Afrosoricida (Afrotheria) from Egypt, with implications for the origin(s) of afrosoricid zalambdodonty. J Vert Paleontol 24:963972.

Shoshani J, Kupsky WJ, Marchant GH (2006): Elephant brain: part I: gross morphology, functions, comparative anatomy, and evolution. Brain Res Bull 70:124-157.

Shoshani J, McKenna MC (1998): Higher taxonomic relationships among extant mammals based on morphology, with selected comparisons of results from molecular data. Mol Phylogenet Evol 9:572-584.

Shultz S, Dunbar R (2010): Encephalization is not a universal macroevolutionary phenomenon in mammals but is associated with sociality. Proc Natl Acad Sci USA 107:21582-21586.

Sigogneau-Russell D, Monbaron M, Russell DE (1988): Découverte de mammifères dans le Mésozoique moyen d'Afrique. CR Acad Sci II 307:1045-1050.

Sigogneau-Russell D, Russell DE (1983): A new dichobunid artiodactyl (Mammalia) from the Eocene of North-West Pakistan. Part III. Reconstruction du moulage endocrânien. Proc Koninklke Nederlandse Akad van Wetenschappen. Series B. Palaeontol, Geol, Phys Chem 86:319-330.

-Simons EL, Holroyd PA, Bown TM (1991): Early Tertiary elephant-shrews from Egypt and the origin of the Macroscelidea. Proc Nat Acad Sci USA 88:9734-9737.
Smit HA, Jansen van Vuuren B, O’Brien PCM, Ferguson-Smith M, Yang F, Robinson TJ (2011): Phylogenetic relationships of elephant-shrews (Afrotheria, Macroscelididae). J Zool 284:133-143.

- Sonntag CF, Woollard HH (1925): A monograph of Orycteropus afer. II. Nervous system, senseorgans and hairs. Proc Zool Soc London 95: $1185-1235$

-Springer MS, Stanhope MJ, Madsen O, de Jong WW (2004): Molecules consolidate the placental mammal tree. Trends Ecol Evol 19: 430-438.

- Stanhope MJ, Waddell VG, Madsen O, de Jong W, Hedges SB, Cleven GC, Kao D, Springer MS (1998): Molecular evidence for multiple origins of Insectivora and for a new order of endemic African insectivore mammals. Proc Nat Acad Sci USA 95:9967-9972.

- Steiper ME, Seiffert ER (2012): Evidence for a convergent slowdown in primate molecular rates and its implications for the timing of early primate evolution. Proc Natl Acad Sci USA 109:6006-6011.

-Stephan H, Bauchot R (1960): Les cerveaux de Chlorotalpa stuhlmanni (Matschie) 1894 et de Chrysochloris asiatica (Linne) 1758 (Insectivora, Chrysochloridae). Mammalia 24:495510

Tabuce R, Asher RJ, Lehmann T (2008): Afrotherian mammals: a review of current data. Mammalia 72:2-14.

- Tabuce R, Marivaux L, Adaci M, Bensalah M, Hartenberger J-L, Mahboubi M, Mebrouk F, Tafforeau P, Jaeger J-J (2007): Early Tertiary mammals from North Africa reinforce the molecular Afrotheria clade. Proc R Soc B Biol Sci 274:1159-1166

Thewissen JGM (1985): Cephalic evidence for the affinities of Tubulidentata. Mammalia 49: 257-284

Thewissen JGM, Domning DP (1992). The role of phenacodontids in the origin of the modern orders of ungulate mammals. J Vertebr Paleontol 12:494-504.

-Van Essen DC (1997): A tension-based theory of morphogenesis and compact wiring in the central nervous system. Nature 385:313318.

-Velez-Juarbe J, Domning DP, Pyenson ND (2012): Iterative evolution of sympatric seacow (Dugongidae, Sirenia) assemblages during the past $\sim 26$ million years. PLoS One $7: \mathrm{e} 31294$.

Welker W (1990): Why does cerebral cortex fissure and fold? A review of determinants of gyri and sulci; in Jones E, Peters A (eds): Cerebral Cortex. New York, Plenum Press, pp 3-136.

Wells LH (1939): The endocranial cast in recent and fossil hyraces (Procaviidae). S Afr J Sci 36: 365-373.

Zack S, Penkrot TA, Bloch JI, Rose KD (2005) Affinities of 'hyopsodontids' to elephant shrews and a Holarctic origin of Afrotheria. Nature 434:497-501. 